\title{
MORPHOLOGICAL AND BEHAVIORAL PLASTICITY OF LARVAL ANURANS IN RESPONSE TO DIFFERENT PREDATORS
}

\author{
RICK A. RELYEA ${ }^{1}$ \\ Department of Biology, University of Michigan, Ann Arbor, Michigan 48109 USA
}

\begin{abstract}
Many organisms can adjust to a changing environment by developing alternative phenotypes that improve their fitness. Our understanding of phenotypic plasticity is largely based upon observations from single species responding to two different environments and measuring a single plastic trait. In this study, I examine predator-induced phenotypic plasticity in tadpoles by observing how six species of larval anurans respond to five different predator environments in 11 different traits (seven morphological traits, two behavioral traits, growth, and development). The results demonstrate that behavioral and morphological plasticity may be ubiquitous in larval anurans. The six prey species exhibited different responses to the same predator species, and each prey exhibited different responses to different predator species. This suggests that responses to a particular predator may not serve as general defense against all predators; rather, prey express predator-specific suites of responses. I also compared relative differences in plasticity among species and among traits. In contrast to earlier findings using only two predator environments, I found that different anurans possess similar degrees of plasticity for most of their traits when reared in a large number of environments. In addition, behavioral traits were always more plastic than morphological traits.

Finally, I examined trait integration to address whether there were apparent trade-offs among traits and limits imposed by the abiotic environment. Trait integration, or the degree of correlated responses among traits across predator environments within a prey species, was very low. This further suggests that the suites of responses are predator specific and may be under independent directions of selection in different predator environments. Trait correlations across prey species indicated that there is an apparent trade-off between tail fin depth and body size. This relationship is supported by selection studies within prey species. Relating the responses to the pond permanence habitat gradient over which the amphibians exist, I found that species inhabiting more temporary ponds possess higher general activity levels, shallower tail fins, and larger bodies; these traits are known to result in more rapid growth. In a companion paper, I quantify the predation risk of the 30 predatorprey combinations and examine the relationships between prey response and predation risk.

Key words: behavior; Bufo americanus; Hyla versicolor; morphology; phenotypic plasticity; Rana catesbeiana; Rana clamitans; Rana pipiens; Rana sylvatica; tadpoles.
\end{abstract}

\section{INTRODUCTION}

Organisms that experience environmental variability must either avoid it or adjust to it. Those organisms that adjust to environmental variability by producing environment-specific phenotypes are said to be phenotypically plastic. The evolution and ecological consequences of adaptive plasticity have been receiving increased attention (Bradshaw 1965, Schlichting 1986, Sultan 1987, West-Eberhard 1989, Via et al. 1995) because ecologists and evolutionary biologists are realizing that phenotypic plasticity is not merely uninteresting developmental noise. Rather, plastic responses are often adaptive responses of organisms in multiple environments. Further, they are often maintained by

\footnotetext{
${ }^{1}$ Present address: Department of Biological Sciences, University of Pittsburgh, Pittsburgh, Pennsylvania 15260 USA. E-mail: relyea+@pitt.edu
}

natural selection (Kingsolver 1995a, Dudley and Schmitt 1996, Van Buskirk and Relyea 1998) and have important implications to the structure of ecological communities (Turner and Mittlebach 1990, Werner and Anholt 1996, Schmitz et al. 1997).

The current state of our knowledge concerning phenotypic plasticity is that many species exhibit the phenomenon and it often appears to be adaptive. Plastic responses are induced by numerous environmental conditions, including abiotic factors such as flooding, temperature, light, and nutrients (Clausen et al. 1941, Hiesey 1953, Cook and Johnson 1968, Scheiner and Goodnight 1984) and biotic factors such as the presence of competitors (Marshall and Jain 1969, Werner and Hall 1976, Moran 1991, Pfennig 1992), herbivores (McNaughton and Chapin 1985, Belsky 1986, Paige and Whitham 1987), and predators (Havel 1987, Harvell 1990, Brönmark and Miner 1992, Smith and Van Buskirk 1995). Likewise, there are numerous possible responses to these environmental factors including 
changes in life history (Crowl and Covich 1990, Skelly and Werner 1990, Black 1993), physiology (Rieck et al. 1960, Rahn 1967), behavior (Sih 1987, Lima and Dill 1990), and morphology (Havel 1987, Harvell 1990). Plastic responses are not necessarily adaptive, but a large percentage of the above studies do demonstrate that the responses are at least in adaptive directions (e.g., prey that reduce their activity in the presence of predators enjoy higher survivorship; Skelly 1994). A few investigators have even been able to quantify the intensity of selection and demonstrate that the current plastic responses are being maintained by disruptive selection in alternative environments (Kingsolver 1995 a, $b$, Dudley and Schmitt 1996, Van Buskirk and Relyea 1998).

In many of the above studies, researchers have examined a single plastic trait in a single species reared in only two environments. While this has been helpful in identifying phenotypically plastic species and the environments that cause the induction of alternative phenotypes, it limits our ability to compare how different species respond to a wide variety of environments and how multiple traits are simultaneously altered. Indeed, the majority of organisms that experience environmental heterogeneity probably experience numerous environments (within or across generations) and alter a suite of traits. Plant ecologists have been particularly thorough in tracking multiple trait changes and have led the way in the interpretation of the causes and consequences of multiple trait plasticity (Hiesey 1953, McGraw and Antonovics 1983, Scheiner and Goodnight 1984, Schlichting and Levin 1984, Crick and Grime 1987). In contrast, we know very little about the responses of animals to a wide variety of environmental conditions, or how animals simultaneously alter multiple traits such as behavior, morphology, and life history.

Examining how different species respond to numerous environments with multiple traits allows one to address several important evolutionary and ecological issues, including differences in plasticity among species, differences in plasticity among traits, potential trade-offs among traits, the functions of traits, and abiotic limits on traits and trait plasticity. Differences in plasticity among species are predicted to occur when species differ in the heterogeneity of their environment. Because heterogeneity selects for plasticity, species that inhabit more heterogeneous environments should be more plastic. However, this prediction appears to be untested. A second issue is whether traits differ in their plasticity; for example, it is commonly believed that behavioral traits are more plastic than morphological traits (West-Eberhard 1989), but this hypothesis is apparently untested. When several traits change simultaneously, we may identify potential trade-offs among traits such that a beneficial trait is induced with some associated fitness cost. Such potential trade-offs may apply both within and across species and help us iden- tify the function of traits. Finally, trait responses may be limited by the presence of abiotic factors. For example, organisms that spend a life stage in temporary environments must rapidly garner resources so they can metamorphose and leave before the environment deteriorates. However, rapidly garnering resources often poses greater predation risk (Azevedo-Ramos et al. 1992, Chovanec 1992, Skelly 1994, Anholt and Werner 1995). Whereas organisms in more permanent environments may be able to avoid predation by reducing resource intake and taking longer to develop, this may not be a viable strategy for organisms in temporary environments. In this case, environmental permanence places an abiotic limit on the type of traits that can be altered. Thus, by investigating plastic responses of numerous species in a wide variety of environments one can better understand the evolution and ecology of phenotypic plasticity.

Amphibians represent an excellent model system for studying phenotypic plasticity because they exhibit a great variety of predator-induced plastic responses and they are quite amenable to experimental manipulation. Predators induce larval amphibians to alter their life history (Skelly and Werner 1990, Jackson and Semlitsch 1993), behavior (Lawler 1989, Werner 1991, Feminella and Hawkins 1994, Horat and Semlitsch 1994), and morphology (Smith and Van Buskirk 1995, McCollum and Van Buskirk 1996, Van Buskirk et al. 1997) in adaptive directions. Amphibian prey respond to chemical cues emitted by predators (Petranka et al. 1987, Kats et al. 1988, McCollum and Leimberger 1997) and this has allowed researchers to simulate predation risk using caged predators without any actual predation on the experimental tadpoles.

In this study, I selected six species of larval anurans, which are naturally arrayed along an environmental gradient of pond permanence, and I quantified behavioral, morphological, developmental, and growth phenotypes in five different predator environments. My hypotheses were the following: (1) the phenotype of a given prey species will differ among predator environments, (2) prey species will differ in phenotypes produced in response to a given predator, (3) prey species will differ in their amount of plasticity, and (4) behavioral phenotypes will be more plastic than morphological phenotypes. In subsequent experiments presented in a companion paper (Relyea 2001), I conducted predation trials for each of the 30 predator-prey combinations to quantify both predation risk as well as predator behavior (a predator's ability to capture, handle, and consume prey) to better understand the strategies that each prey species uses in responding to each predator. Throughout these papers, I use the term "phenotype" to refer to a specific trait value and "response" to refer to a change in trait value.

\section{Methods}

I separated the six anuran species into two groups based on their breeding phenology and selected pred- 
ators that spanned a range of sizes (Relyea 2001) and are common in natural ponds in Michigan. The spring breeders (March-May) were wood frogs (Rana sylvatica), leopard frogs ( $R$. pipiens), and American toads (Bufo americanus). Their predators were mudminnows (Umbra limi), dragonfly larvae (Anax spp.), eastern red-spotted newts (Notophthalmus viridescens), and dytiscid beetle larvae (for wood frogs, the dytiscid for the first 2 wk was Colymbetes sp. followed by Dytiscus sp.; only Dytiscus was used for leopard frogs and toads). Extensive surveys on the Edwin S. George Reserve (ESGR) in southeast Michigan indicate that wood frogs commonly overlap with dragonflies, newts, and dytiscid beetles, but rarely overlap with mudminnows. In contrast leopard frogs and toads commonly overlap with all four predator species (E. E. Werner, unpublished data).

The summer breeders (June-August) were bullfrogs ( $R$. catesbeiana), green frogs ( $R$. clamitans), and gray treefrogs (Hyla versicolor). Their predators were mudminnows, dragonfly larvae, tiger salamander larvae (Ambystoma tigrinum), and water bugs (Belostoma sp.). Whereas green frogs and treefrogs commonly overlap with all four predators, bullfrogs rarely overlap with tiger salamanders (E. E. Werner et al., unpublished data). All amphibians and their predators were collected on the ESGR and the Michigan Department of Natural Resources' Saline Fish Hatchery. Amphibians were collected as eggs and hatched in wading pools containing aged well water; thus, prior to the initiation of the experiments, all tadpoles were predator naive.

Experimental units were plastic tubs $(26 \times 38 \times 14$ $\mathrm{cm}$ ) containing $7 \mathrm{~L}$ of aged well water. At one end of the tub I placed a predator cage constructed of 1-mm mesh mosquito netting $(40 \times 40 \mathrm{~cm})$ folded into a bag and stapled to two pieces of wood $(30 \times 5 \times 0.5 \mathrm{~cm})$. The cage was kept closed by a rubber band on each end. Ten newly hatched tadpoles (Gosner stage 25, Gosner 1960) were added to each tub (wood frogs, 19.5 $\pm 0.6 \mathrm{mg}$; leopard frogs, $30.2 \pm 1.0 \mathrm{mg}$; toads, 15.9 $\pm 0.9 \mathrm{mg}$; bullfrogs, $18.6 \pm 1.0 \mathrm{mg}$; green frogs, 21.0 $\pm 1.3 \mathrm{mg}$; and gray treefrogs, $22.8 \pm 1.6 \mathrm{mg}$ ). I fed the tadpoles a 3:1 mixture (by mass) of rabbit chow and Tetramin fish flakes (Tetra, Blacksburg, Virginia, USA) three times per week at a per-capita rate of $6 \%$ of mean mass across treatments within a species. Predators were also fed three times per week by introducing 3-10 tadpoles (total mass of $\sim 100 \mathrm{mg}$ ) into the predator cages. With one exception, predators were fed conspecific anurans. Leopard frog larvae were in short supply; thus, their predators were fed wood frog larvae. Subsequent experiments have demonstrated that leopard frog behavior and morphology does not differ when Anax predators were fed either wood frogs or leopard frogs (Relyea and Werner 2000; unpublished data).

I placed the tubs on shelves at the University of Michigan's Experimental Pond Facility of the ESGR. All treatments were replicated four times. Treatments within a species were blocked by shelf, and a bank of fluorescent lights placed over each shelf (controlled by timers) provided a 14:10 light/dark cycle. Every 7 d, tadpoles were weighed and the tub water was changed. At the end of a 5-wk exposure to caged predators, all tadpoles were preserved in $10 \%$ formalin.

\section{Data collection and analysis of behavioral, developmental, and growth phenotypes}

Activity and spatial distribution of the tadpoles were quantified by slowly approaching the tubs and observing the experimental populations. Active tadpoles were defined as those either swimming or feeding; spatial distribution was quantified by counting animals on either side of a line drawn down the center of the tub demarcating the predator and no-predator sides of the tub. Tanks were observed 30-40 times over a period of $5 \mathrm{wk}$. Because of mortality during the experiment, the number of animals active and the number of animals on the predator-cage side of the tank were converted to proportions of the total animals alive in the tank at the time of observation.

I conducted three analyses to examine differences in behavior, development, and growth among prey and predator treatments. The first two analyses compared the five predator treatments that were unique to either the three spring- or three summer-breeding anurans. The third analysis compared the three predator treatments that were common to all six anurans (no predator, Umbra, and Anax; henceforth termed the "combined analysis"). For each analysis, one multivariate analysis of variance (MANOVA) was conducted on the activity and spatial distribution responses and another MANOVA was conducted on the growth (final-initial mass) and development (Gosner stage; Gosner 1960) responses. In all cases, the responses were the mean observations for each tub within each of the four replicates. Because of differences in breeding phenology, tanks could not be randomized with respect to species. Although originally designed as a randomized block design for each prey species, analyses of each prey species separately indicated that only one response (activity) had a significant block effect in only one species (treefrog). Because this was the only significant block effect out of a potential 78, blocks were dropped to simplify the large combined analyses. Behavioral responses were arcsine square-root transformed, whereas growth and developmental responses were log-transformed to meet the assumptions of the analysis. Pairwise comparisons were conducted using Fisher's mean comparison test.

\section{Data collection and analysis of morphological traits}

Tadpole morphology was measured by tracing video images of preserved tadpoles using the BioScan Optimas image analysis system (Optimus Bioscan, Bothell, Washington, USA). For each tadpole, I traced the outline of the body, tail fin, and tail muscle from a 

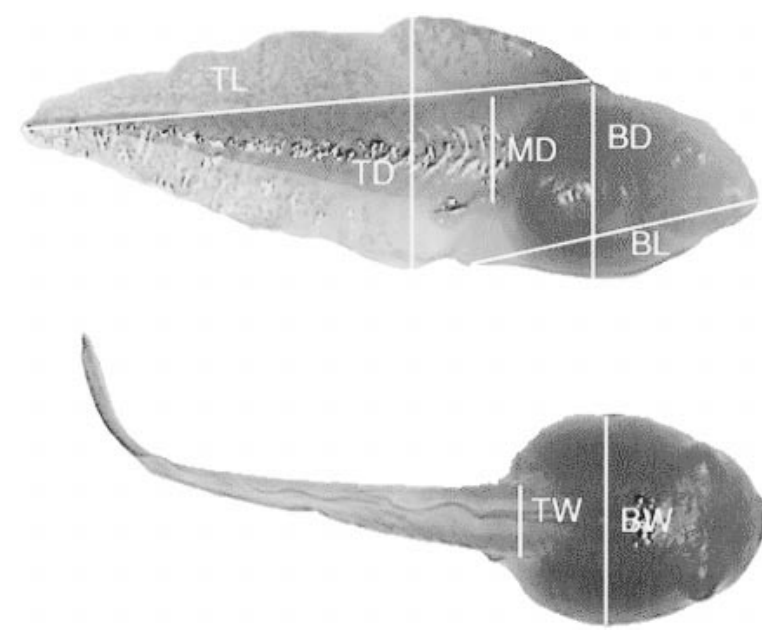

FIG. 1. The lateral view (above) and dorsal view (below) of a wood frog tadpole demarcated with the seven linear measures that were used in the analysis of morphological plasticity $(\mathrm{BD}=$ body depth, $\mathrm{BL}=$ body length, $\mathrm{BW}=$ body width, $\mathrm{TD}=$ tail depth, $\mathrm{TL}=$ tail length, $\mathrm{MD}=$ muscle depth, and TW = tail muscle width).

lateral view and the body and tail muscle from a dorsal view. Because the tadpole body is rounded, I placed a glass plate under the tadpole's tail to provide an undistorted lateral view. From these tracings, seven linear measurements were calculated: maximum tail fin height, maximum tail length, maximum tail muscle height, maximum body height, maximum body length (all from the lateral view), maximum tail muscle width, and maximum body width (from the dorsal view; Fig. 1). Each tadpole also was weighed and staged using the standard larval stages of Gosner (1960).

To compare morphology among anuran species and among predator treatments, I log-transformed all measurements and conducted a principal components analysis (PCA) to estimate overall size. The two tail fin dimensions and the three body dimensions for every individual were entered into the PCA and scores from the first principal component (PC-1) were saved. The five dimensions had high positive loadings $(>0.98)$, indicating that PC-1 was a good estimate of tadpole size; it explained $97 \%$ of the variance. I then regressed the morphological measurements on the PC- 1 scores to remove differences in morphology due to size (a morphometric procedure termed shearing, Bookstein 1991). The regression residuals were saved and the mean residuals for each tub were calculated to represent an experimental unit. Morphological traits were analyzed in a similar fashion as the behavioral traits using three MANOVAs: a spring analysis, a summer analysis, and a combined analysis. Pairwise comparisons were conducted using Fisher's mean comparison test.

\section{Trait correlations}

Correlations among traits across predator species permitted me to clearly address whether prey were us- ing a scaled suite of traits against different predators (a high number of correlations among traits) or whether prey were using unique suites of traits against each predator species (a low number of correlations among traits). Further, trait correlations within a prey species among predator environments may suggest potential phenotypic trade-offs that affect the evolution of plastic responses (Via and Lande 1985, 1987). To address this question, I constructed a Pearson correlation matrix to determine whether the 11 traits were correlated across predator environments within each of the six prey species. Each trait was represented by the 20 trait values that came from the 20 tubs. A Bonferroni adjustment was made for conducting 55 correlations.

To address the second question of potential trait trade-offs across species, I constructed a Pearson correlation matrix of the 11 traits across the six species within each of the common predator environments (no predator, Umbra, and Anax). Each trait was represented by the 24 trait values that came from the four replicates in a given environment from each of the six prey species. Results from this test indicate potential trade-offs in prey design among species (e.g., tadpole species with deep tails may also have short bodies). Again, a Bonferroni adjustment was made for conducting 55 correlations.

\section{Comparisons of plasticity}

Because the experiment contained a high number of prey, environments, and traits, it represented an excellent opportunity to compare the plasticity among species and among traits. Scheiner and Goodnight (1984) have suggested using the coefficient of variation across treatment means as an effective relative measure of phenotypic plasticity. Such an index accounts for limitations on plasticity imposed by a limited scope of potential response. For example, a generally inactive prey is more limited in reducing its activity in the presence of a predator than is a more active prey. This index of plasticity has the additional advantage of allowing a standardized comparison of traits measured in different units, for example, morphological traits vs. behavioral traits.

To compare plasticity among anurans and traits, I began by calculating the mean response for each tub. I then took the five tubs that represented the first replicate of the five predator treatments (within a species) and I calculated the coefficient of variation of the five tub means. This produced a single replicate estimate of plasticity for a particular species. I continued to do these calculations for the second, third, and fourth replicates of the treatments, thus providing four replicate measures of plasticity for each prey's traits. Because the morphological traits were residual measures, traits that changed little had residuals of nearly zero, which would greatly inflate coefficients of variation. To alleviate this bias, I first added a unique constant to the residuals of each morphological trait; each trait's con- 
TABLE 1. $P$ values from the MANOVA on behavioral, growth, and developmental responses of the three spring-breeding anurans to five predator treatments.

\begin{tabular}{|c|c|c|c|c|c|c|}
\hline \multirow[b]{2}{*}{ Factor } & \multirow{2}{*}{$\begin{array}{l}\text { Multivariate } \\
\text { responses }\end{array}$} & \multicolumn{2}{|c|}{ Univariate responses } & \multirow{2}{*}{$\begin{array}{l}\text { Multivariate } \\
\text { responses }\end{array}$} & \multicolumn{2}{|c|}{ Univariate responses } \\
\hline & & Growth & Development & & Activity & Avoidance \\
\hline Predator & 0.330 & 0.636 & 0.203 & $<0.001$ & $<0.001$ & $<0.001$ \\
\hline Prey & $<0.001$ & $<0.001$ & $<0.001$ & $<0.001$ & $<0.001$ & $<0.001$ \\
\hline Predator $\times$ Prey & 0.444 & 0.515 & 0.356 & $<0.001$ & $<0.001$ & 0.004 \\
\hline
\end{tabular}

stant was the mean value of the trait prior to the masstrait regression that produced the residuals. I conducted three MANOVAs (see Methods: Data collection section) on these plasticity data to determine whether there were overall differences in plasticity among prey and whether certain traits were more plastic than others. I also conducted an alternative, and more complex, analysis of comparative plasticity using resampling statistics for a subset of the data. I used a Monte Carlo approach on a subset of the data to derive 1000 estimates of trait plasticity based on random combinations of a single replicate from each predator treatment and then randomly sampled from this distribution of estimates to test whether species differed ( $<5 \%$ of all samples) in their plasticity of the trait. The results from this resampling analysis were in agreement with the simpler former analysis; thus, I only present results from the former analysis.

\section{RESULTS}

The results are complex due to the large number of treatment combinations and responses, and so the results below are separated into growth and developmental responses, behavioral responses, and morphological responses. For each section, the results are presented as follows: (1) the analysis of leopard frogs, wood frogs, and toads reared with five spring predators, (2) the analysis of bullfrogs, green frogs, and treefrogs reared with five summer predators, and (3) the combined analysis of all six anuran species reared with the three common predator treatments. All predator effects are comparisons to the no-predator control unless otherwise noted. Because of the very large number of possible mean comparisons, only a subset of mean comparisons will be mentioned. More detailed comparisons can be obtained from the accompanying figures.

\section{Growth and developmental responses}

Larval growth and development were unaffected by the presence of caged predators in the two seasonal analyses, but did vary greatly among anuran species (Tables 1-3, Fig. 2). In the combined analysis, leopard frogs and treefrogs were the fastest growing prey species (they did not differ from each other, $P=0.594$ ), followed by wood frogs, toads, bullfrogs, and green frogs, respectively (for all other pairwise comparisons, $P<0.001)$. Developmental rates were equally low in bullfrogs and green frogs $(P=0.296)$ and increasingly rapid in leopard frogs, wood frogs, treefrogs, and toads, respectively (for all other pairwise comparisons, $P<$ $0.001)$.

\section{Behavioral responses}

All significant activity responses to predators were activity reductions (Tables $1-3$, Fig. 3 ). In the spring analysis, toads reduced their activity with Umbra, Dytiscus, and Anax $(P<0.03)$, but not in the presence of Notophthalmus $(P=0.126)$. Leopard frogs became less active with Umbra and Anax $(P<0.004)$ but not in the presence of Notophthalmus and Dytiscus $(P>$ $0.3)$. Wood frogs reduced their activity with Umbra, Anax, and Notophthalmus $(P<0.01)$ but not in the presence of Dytiscus $(P=0.127)$; the response to Umbra was stronger than the response to the other three predators $(P<0.002)$.

Among the summer anurans, treefrogs reduced their activity with Umbra and Anax $(P<0.005)$ but did not respond to Belostoma and Ambystoma $(P>0.25)$. Bullfrogs became less active with all four predators $(P<$ $0.005)$ and green frogs reduced their activity with $\mathrm{Be}$ lostoma and Anax $(P<0.02)$ but not in the presence of Umbra and Ambystoma $(P>0.07)$. The response to Anax was stronger than the response to all three other predators $(P<0.04)$. In a comparison of all six species

TABle 2. $P$ values from the MANOVA on behavioral, growth, and developmental responses of the three summer-breeding anurans to five predator treatments.

\begin{tabular}{|c|c|c|c|c|c|c|}
\hline \multirow[b]{2}{*}{ Factor } & \multirow{2}{*}{$\begin{array}{l}\text { Multivariate } \\
\text { responses }\end{array}$} & \multicolumn{2}{|c|}{ Univariate responses } & \multirow{2}{*}{$\begin{array}{l}\text { Multivariate } \\
\text { responses }\end{array}$} & \multicolumn{2}{|c|}{ Univariate responses } \\
\hline & & Growth & Development & & Activity & Avoidance \\
\hline Predator & 0.487 & 0.718 & 0.235 & $<0.001$ & $<0.001$ & $<0.001$ \\
\hline Prey & $<0.001$ & $<0.001$ & $<0.001$ & $<0.001$ & $<0.001$ & 0.002 \\
\hline Predator $\times$ Prey & 0.136 & 0.165 & 0.151 & 0.003 & 0.200 & $<0.001$ \\
\hline
\end{tabular}


TABLE 3. $\quad P$ values from the MANOVA on behavioral, growth, and developmental responses of all six anurans to the three common predator treatments.

\begin{tabular}{|c|c|c|c|c|c|c|}
\hline \multirow[b]{2}{*}{ Factor } & \multirow{2}{*}{$\begin{array}{l}\text { Multivariate } \\
\text { responses }\end{array}$} & \multicolumn{2}{|c|}{ Univariate responses } & \multirow{2}{*}{$\begin{array}{l}\text { Multivariate } \\
\text { responses }\end{array}$} & \multicolumn{2}{|c|}{ Univariate responses } \\
\hline & & Growth & Development & & Activity & Avoidance \\
\hline Predator & 0.987 & 0.998 & 0.849 & $<0.001$ & $<0.001$ & $<0.001$ \\
\hline Prey & $<0.001$ & $<0.001$ & $<0.001$ & $<0.001$ & $<0.001$ & $<0.001$ \\
\hline Predator $\times$ Prey & 0.163 & 0.637 & 0.070 & $<0.001$ & $<0.001$ & $<0.001$ \\
\hline
\end{tabular}

in the absence of predators, the lowest activity was exhibited by green frogs $(P \leq 0.02)$ with increasing activity in leopard frogs, bullfrogs, treefrogs, wood frogs, and toads, respectively.

All significant spatial responses of the prey were away from the caged predator. In the spring analysis, toads avoided Dytiscus and Anax $(P<0.05)$, but did not respond to Umbra and Notophthalmus $(P>0.4)$. Leopard frogs avoided Umbra and Anax $(P \leq 0.001)$, but not Notophthalmus and Dytiscus $(P>0.1)$. Wood frogs avoided Anax $(P<0.001)$, but not Umbra, Notophthalmus, or Dytiscus $(P>0.2)$; the response to Anax was stronger than the responses to Umbra, Notophthalmus, or Dytiscus $(P \leq 0.006)$.

In the summer analysis, treefrogs avoided all four predators $(P \leq 0.05)$. In addition, the response to $U m$ bra was stronger than the response to Belostoma $(P=$ 0.008). Bullfrogs avoided Umbra, Ambystoma, and Anax $(P \leq 0.01)$ but did not avoid Belostoma $(P=$ 0.250). Green frogs only avoided Anax $(P=0.007)$ and the avoidance was stronger than with the other three predators $(P \leq 0.002)$.

\section{Morphological responses}

All anurans altered their morphology in the presence of at least one of the caged predators. In the analysis of the spring-breeding anurans (Table 4, Figs. 4 and 5), toads responded to Umbra by developing shallower and longer tails $(P<0.05)$ and responded to Anax by developing shallower tails $(P=0.019)$. Umbra-induced tails were shallower than Notophthalmus- and Dytiscus-induced tails $(P \leq 0.02)$. Leopard frogs had deeper tails and shorter bodies in the presence of $U m$ bra $(P=0.000)$ but not in the presence of the other predators $(P>0.15)$. Wood frogs did not alter any morphological traits in the presence of Dytiscus and Notophthalmus $(P>0.15)$ but did alter their morphology in the presence of Umbra and Anax. When Anax were present, wood frogs developed deeper tails $(P=0.027)$. When Umbra were present, wood frogs developed deeper tails and deeper muscles $(P<0.005)$ along with deeper and shorter bodies $(P \leq 0.002)$.

In the analysis of summer-breeding anurans (Table 5, Figs. 4 and 5), bullfrogs only responded by increasing their tail fin length in the presence of Umbra and Ambystoma $(P \leq 0.02)$. Green frogs responded to all four predators. When Umbra were present, green frogs developed shorter $(P<0.001)$ and nearly shallower $(P$ $=0.070)$ tails, narrower tail muscles $(P=0.010)$, and wider bodies $(P=0.028)$. In the presence of Anax, green frogs developed shorter tails $(P<0.001)$ and wider bodies $(P=0.013)$. When Ambystoma were present, green frogs developed shorter and shallower tails $(P<0.001)$ and wider and longer bodies $(P<0.05)$. Belostoma induced shorter $(P<0.001)$ and nearly shallower $(P=0.065)$ tails and deeper and wider bodies

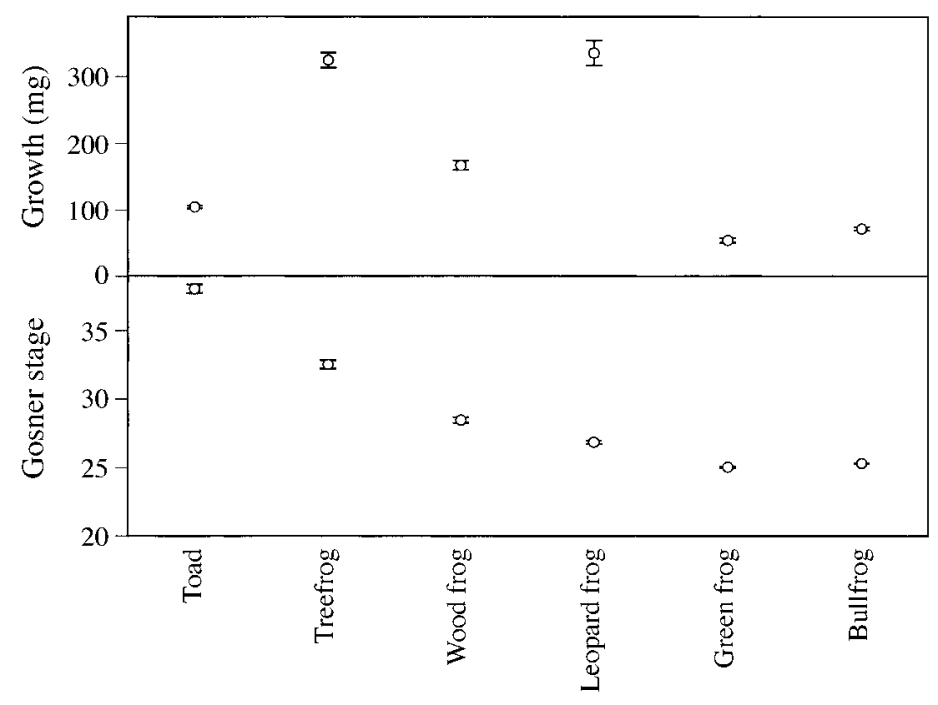

FIG. 2. Growth and developmental stages (Gosner 1960; mean $\pm 1 \mathrm{SE}$ ) of six larval anurans. There were no effects of predator environments; thus, the presented data are averaged across predator environments. 


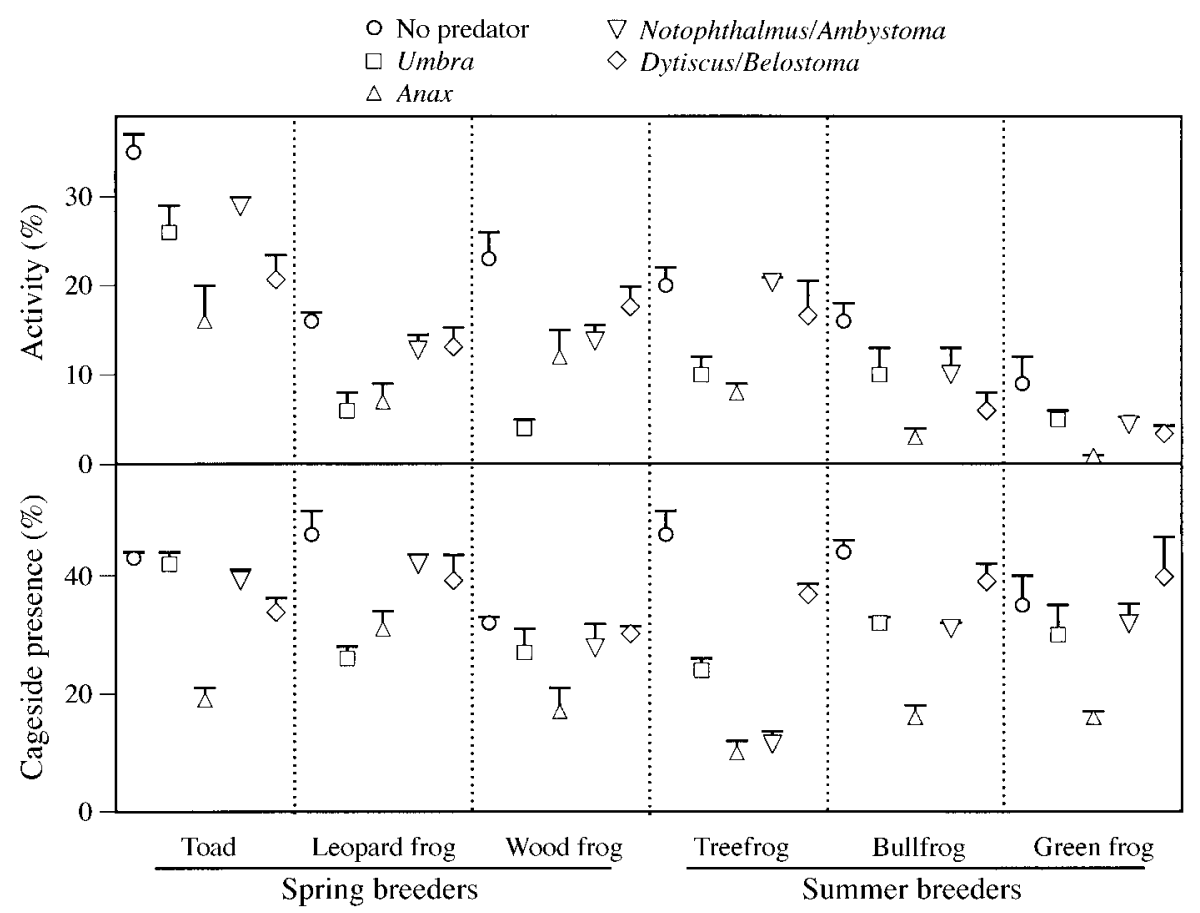

FIG. 3. Percentage activity and the percentage of animals on the predator side of the tub (mean $+1 \mathrm{SE}$ ) for six species of larval anurans reared in the presence of five predator environments. The spring-breeding anurans were reared in the presence of no predators, Umbra, Anax, Notophthalmus, or Dytiscus, whereas the summer-breeding anurans were reared in the presence of no predators, Umbra, Anax, Ambystoma, or Belostoma.

$(P<0.05)$. There were many differences among predators as well, including narrower muscles in the presence of Umbra than in the presence of Anax and Belostoma $(P<0.05)$. The responses of treefrogs were quite different. Umbra induced longer tails $(P=$ $0.001)$, wider muscles $(P=0.041)$, and shallower bodies $(P=0.004)$. In contrast, Anax induced nearly longer $(P=0.098)$ and deeper tails $(P=0.062)$, wider muscles $(P=0.004)$, and nearly shallower and shorter bodies $(P \leq 0.07)$. Ambystoma induced longer tails ( $P$ $=0.006)$, wider muscles $(P=0.007)$ and shallower bodies $(P=0.011)$ whereas Belostoma induced shallower $(P=0.050)$ and nearly longer tails $(P=0.086)$, wider muscles $(P=0.012)$, and wider bodies $(P=$ 0.014). Again, there were many differences in morphological responses of treefrogs among predator treatments, including deeper tails in the presence of Anax and Ambystoma than in the presence of Umbra and Belostoma $(P<0.05)$.

The combined analysis of all six anuran species in the presence of the three common treatments (no predator, Umbra, and Anax) allowed a comparison of general morphology and differences in response across species (Table 6, Figs. 4 and 5). In all three treatments, toads had consistently shallower tail fins and wider bodies than the other five anuran species $(P<0.03)$ whereas bullfrogs, leopard frogs, and toads all had relatively shorter tail fins than green frogs, wood frogs, and treefrogs $(P<0.001)$. In the presence of either predator, larval green frogs and treefrogs had relatively shallow bodies $(P<0.007)$.

\section{Plasticity comparisons}

The comparison of plasticity among prey species and among traits indicated that the two interacted in all

TABLE 4. $\quad P$ values from the MANOVA on morphological responses of the three spring-breeding anurans to five predator treatments.

\begin{tabular}{|c|c|c|c|c|c|c|c|c|}
\hline \multirow[b]{2}{*}{ Factor } & \multirow[b]{2}{*}{$\begin{array}{l}\text { Multivariate } \\
\text { responses }\end{array}$} & \multicolumn{7}{|c|}{ Univariate responses } \\
\hline & & $\begin{array}{l}\text { Tail fin } \\
\text { depth }\end{array}$ & $\begin{array}{l}\text { Tail fin } \\
\text { length }\end{array}$ & $\begin{array}{c}\text { Tail muscle } \\
\text { depth }\end{array}$ & $\begin{array}{l}\text { Tail muscle } \\
\text { width }\end{array}$ & $\begin{array}{l}\text { Body } \\
\text { depth }\end{array}$ & $\begin{array}{l}\text { Body } \\
\text { length }\end{array}$ & $\begin{array}{l}\text { Body } \\
\text { width }\end{array}$ \\
\hline Predator & 0.010 & 0.692 & 0.008 & 0.002 & 0.473 & 0.008 & $<0.001$ & 0.129 \\
\hline Prey & $<0.001$ & $<0.001$ & $<0.001$ & $<0.001$ & 0.777 & $<0.001$ & $<0.001$ & $<0.001$ \\
\hline Predator $\times$ Prey & 0.006 & 0.001 & 0.373 & 0.009 & 0.782 & 0.009 & 0.007 & 0.373 \\
\hline
\end{tabular}




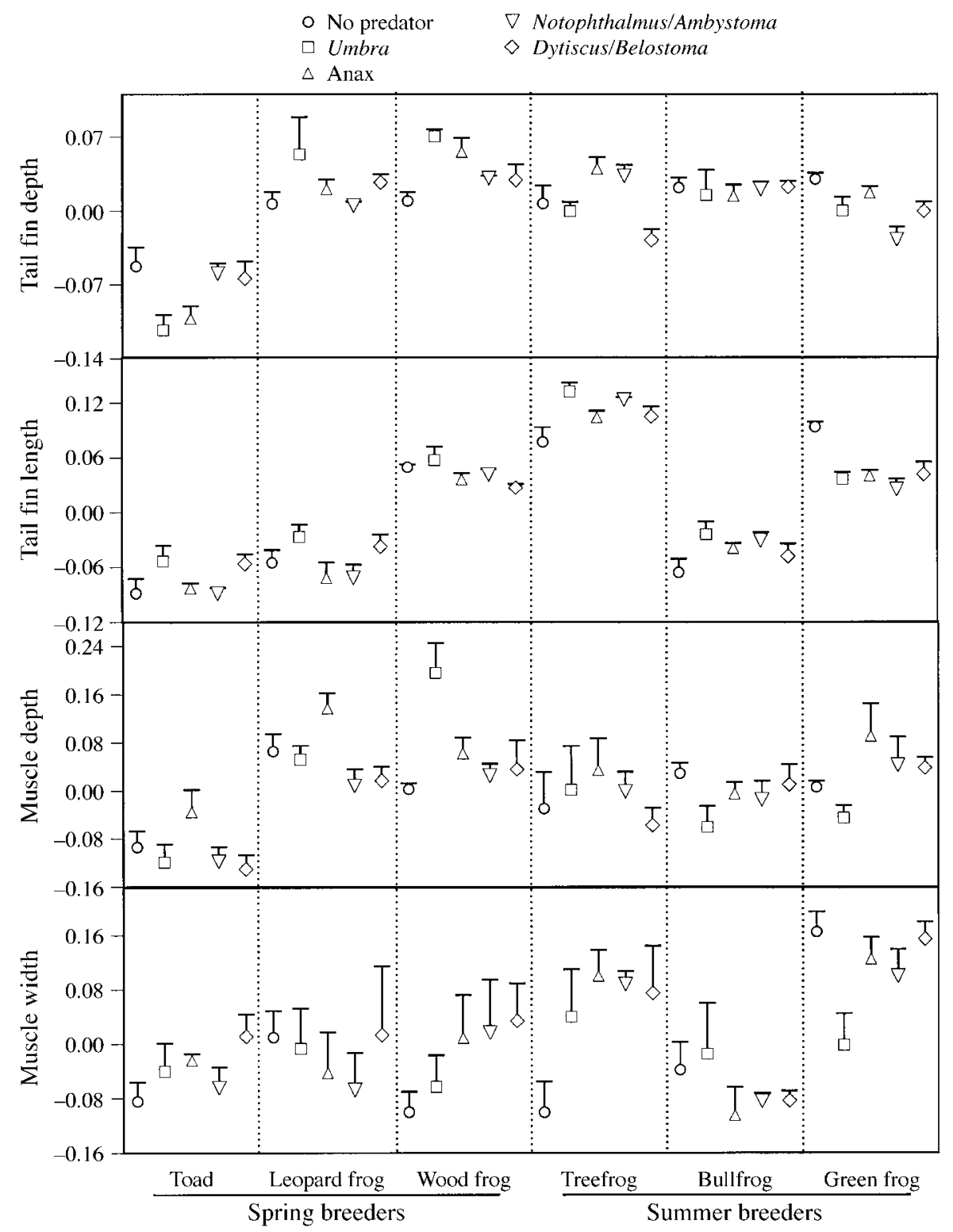

FIG. 4. Relative tail morphology (mean $+1 \mathrm{SE}$ ) of six species of larval anurans reared in the presence of five predator environments. Differences in overall size among tadpoles were removed prior to analysis (see Methods: Data collection). The spring-breeding anurans were reared in the presence of no predators, Umbra, Anax, Notophthalmus, or Dytiscus, whereas the summer-breeding anurans were reared in the presence of no predators, Umbra, Anax, Ambystoma, or Belostoma.

three analyses (multivariate Wilks' $P<0.002$ ) and thus required separate analyses to determine how the traits differed in plasticity within each species and how the species differed in plasticity for each trait (Fig. 6). In both the spring and summer analyses, behavioral traits were consistently more plastic than morphological traits within each species $(P<0.004)$. Among morphological traits in the two analyses, muscle width was more plastic than the other six traits in wood frogs $(P$ $<0.002)$, leopard frogs $(P<0.007)$, and treefrogs $(P$ $<0.040$ ). Muscle width also tended to be the most plastic morphological trait in toads; it was nearly more plastic than muscle depth $(P=0.080)$ and significantly more plastic than the other five morphological traits $(P$ $<0.04)$. There were no differences in plasticity of morphological traits in bullfrogs $(P>0.10)$ and green frogs $(P>0.25)$. The remaining pairwise comparisons of trait plasticity within species revealed no differences $(P>0.05)$.

The second approach to compare magnitudes of plasticity was to compare how species differed in the plasticity of a particular trait (Fig. 6). In the spring analysis, wood frogs had more plastic activity than toads $(P=$ 0.009 ) and more plastic body depths than leopard frogs 


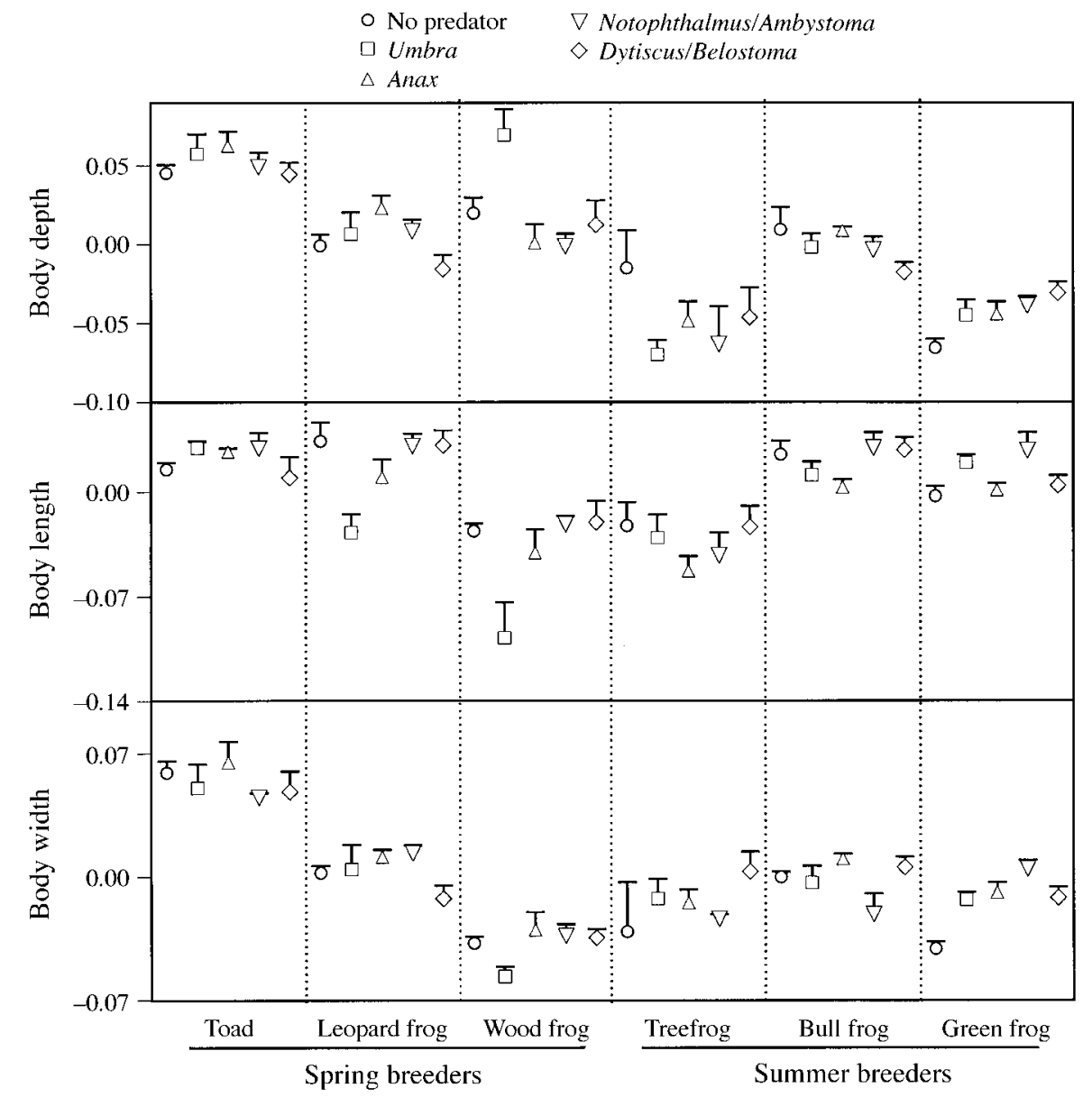

FIG. 5. Relative body morphology (mean $+1 \mathrm{SE}$ ) of six species of larval anurans reared in the presence of five predator environments. Differences in overall size among tadpoles were removed prior to analysis (see Methods: Data collection). The spring-breeding anurans were reared in the presence of no predators, Umbra, Anax, Notophthalmus, or Dytiscus, whereas the summer-breeding anurans were reared in the presence of no predators, Umbra, Anax, Ambystoma, or Belostoma.

and toads $(P<0.05)$. Both wood frogs and leopard frogs had more plastic muscle width than toads $(P<$ $0.01)$. In the summer analysis, the only difference in plasticity was that treefrogs had more plastic spatial avoidance than green frogs and bullfrogs $(P<0.002)$. In the combined analysis, in which overall plasticity is only based upon three environments, treefrogs had more plastic avoidance than wood frogs, leopard frogs, toads, and green frogs $(P<0.04)$ and nearly more than bullfrogs $(P=0.062)$. Wood frogs and leopard frogs had more body length plasticity than bullfrogs, green frogs, and toads $(P<0.04)$ but did not differ from each other or from treefrogs $(P>0.1)$. The six prey did not differ in their plasticity of the remaining traits.

\section{Trait correlations}

The first analysis of trait correlations was conducted within each prey species across all predator environments (Fig. 7). Of the 55 possible correlations between pairs of traits, bullfrogs expressed no significant (Bonferroni-adjusted) correlations. Leopard frogs and toads each expressed a single pair of correlated traits; toads exhibited a positive correlation between activity level and spatial avoidance of predators $(P=0.013)$ whereas leopard frogs exhibited a positive correlation between growth and development $(P=0.008)$. Treefrogs also exhibited positive correlations between growth and development $(P=0.004)$ as well as correlations between body length and development $(P=0.016)$. Green frogs exhibited significant correlations; predator environments that induced shorter tails also induced wider $(P$ $=0.009)$ and deeper $(P=0.016)$ bodies. As different predator environments induced shallower tail fins, they also induced longer bodies $(P=0.009)$. Wood frogs exhibited the highest number of significant correlations; predator environments that induced deeper tail fins also induced deeper tail muscles $(P=0.019)$ and shorter bodies $(P=0.003)$, environments that induced deeper muscles also induced deeper bodies $(P=0.003)$ and shorter bodies $(P<0.001)$, and environments that tended to produce faster development also produced 
TABLE 5. $\quad P$ values from the MANOVA on morphological responses of the three summer-breeding anurans to five predator treatments.

\begin{tabular}{lcrrrrrrr}
\hline \hline & & \multicolumn{7}{c}{ Univariate responses } \\
\cline { 3 - 9 } \multicolumn{1}{c}{ Factor } & $\begin{array}{c}\text { Multivariate } \\
\text { responses }\end{array}$ & $\begin{array}{c}\text { Tail fin } \\
\text { depth }\end{array}$ & \multicolumn{2}{c}{ Tail fin } & Tail muscle & Tail muscle & Body \\
length & depth & width & $\begin{array}{c}\text { Body } \\
\text { length }\end{array}$ & $\begin{array}{c}\text { Body } \\
\text { width }\end{array}$ \\
\hline Predator & 0.227 & 0.053 & 0.411 & 0.234 & 0.713 & 0.595 & 0.113 & 0.030 \\
Prey & $<0.001$ & 0.129 & $<0.001$ & 0.250 & $<0.001$ & $<0.001$ & $<0.001$ & 0.031 \\
Predator $\times$ Prey & $<0.001$ & 0.004 & $<0.001$ & 0.521 & 0.015 & 0.065 & 0.313 & 0.038 \\
\hline
\end{tabular}

greater growth $(P<0.001)$ and longer bodies $(P=$ $0.005)$.

The second type of trait integration analysis determined phenotypic relationships among the six prey species within single predator environments (Fig. 8). In the no-predator environment, more active prey species exhibited faster development $(P<0.001)$, larger bodies $(P<0.05)$, and shallower tails $(P=0.045)$. Prey species with larger bodies also had shorter tails $(P<0.04)$. In the Umbra treatment, prey species that were more active were more advanced in development $(P<$ $0.001)$, and had wider bodies $(P=0.020)$ and shallower tails $(P=0.005)$. Deeper tails and muscles were associated with shorter $(P<0.03)$ and narrower bodies $(P=0.001)$. In the presence of Anax, faster developing tadpoles continued to be associated with higher activity $(P=0.005)$ and shallower tails $(P=0.007)$. Species with deep and long tails had small bodies $(P \leq 0.05)$. Thus, the pattern among species is that rapidly developing prey possess high activity and shallow tails, and that large tails are associated with small bodies.

\section{Discussion}

The results of this study suggest that behavioral and morphological responses to predators may be widespread among larval amphibians. Behavioral responses have been repeatedly observed in larval anurans and caudates (Lawler 1989, Werner 1991, Tejedo 1993, Anholt et al. 1996, Van Buskirk and Yurewicz 1998), but morphological responses to predators only have been investigated in four species of anurans. Predator-induced morphological responses have been found in chorus frogs (Pseudacris triseriata), Cope's gray treefrogs (Hyla chrysocelis), and wood frogs but not in spring peepers (P. crucifer) (Smith and Van Buskirk 1995, McCollum and Van Buskirk 1996, Van Buskirk et al. 1997, Van Buskirk and Relyea 1998). My ex- amination of six additional species of larval anurans indicates that eight of nine larval anurans thus far examined alter their morphology in the presence of predators. This ubiquity of morphological responses among anuran species located primarily in the midwestern United States may extend to species in other regions of the world as well as to other aquatic vertebrates including larval caudates and fish (see Brönmark and Miner 1992 for the one known fish example). This would be consistent with studies of aquatic invertebrate taxa in which predator-induced morphological changes are ubiquitous (Havel 1987).

\section{Prey-specific responses}

All of the larval anurans exhibited some form of predator-induced plasticity but the magnitude and direction depended on the particular predator-prey combination. Often, different prey species did not respond to a particular predator the same way. For example, in the presence of Umbra (relative to the no-predator treatment), bullfrogs and treefrogs exhibited no change in tail fin depth, leopard frogs and wood frogs increased their tail fin depth, and green frogs and toads decreased their tail fin depth. Because the predator environments did not affect growth or development in any of the tadpole species, these morphological changes were not the result of differential allometric growth, a conclusion which is supported by previous work (Relyea and Werner 2000).

Prey-specific morphological responses to a given predator are common, ranging from differences in species-level responses to differences in clone-level responses. The majority of morphological examples come from studies of aquatic invertebrates. For example, some species of Daphnia respond to particular invertebrate predators, whereas other species do not; in fact, even different clones of $D$. pulex exhibit specific

TABle 6. $P$ values from the MANOVA on morphological responses of the six anurans to no predator, caged Anax, and caged Umbra.

\begin{tabular}{|c|c|c|c|c|c|c|c|c|}
\hline \multirow[b]{2}{*}{ Factor } & \multirow[b]{2}{*}{$\begin{array}{l}\text { Multivariate } \\
\text { responses }\end{array}$} & \multicolumn{7}{|c|}{ Univariate responses } \\
\hline & & $\begin{array}{l}\text { Tail fin } \\
\text { depth }\end{array}$ & $\begin{array}{l}\text { Tail fin } \\
\text { length }\end{array}$ & $\begin{array}{c}\text { Tail muscle } \\
\text { depth }\end{array}$ & $\begin{array}{l}\text { Tail muscle } \\
\text { width }\end{array}$ & $\begin{array}{l}\text { Body } \\
\text { depth }\end{array}$ & $\begin{array}{l}\text { Body } \\
\text { length }\end{array}$ & $\begin{array}{l}\text { Body } \\
\text { width }\end{array}$ \\
\hline Predator & 0.009 & 0.889 & 0.003 & 0.043 & 0.420 & 0.812 & 0.011 & 0.035 \\
\hline Prey & $<0.001$ & $<0.001$ & $<0.001$ & $<0.001$ & 0.001 & $<0.001$ & $<0.001$ & $<0.001$ \\
\hline Predator $\times$ Prey & $<0.001$ & 0.004 & 0.002 & 0.013 & 0.052 & $<0.001$ & $<0.001$ & 0.474 \\
\hline
\end{tabular}



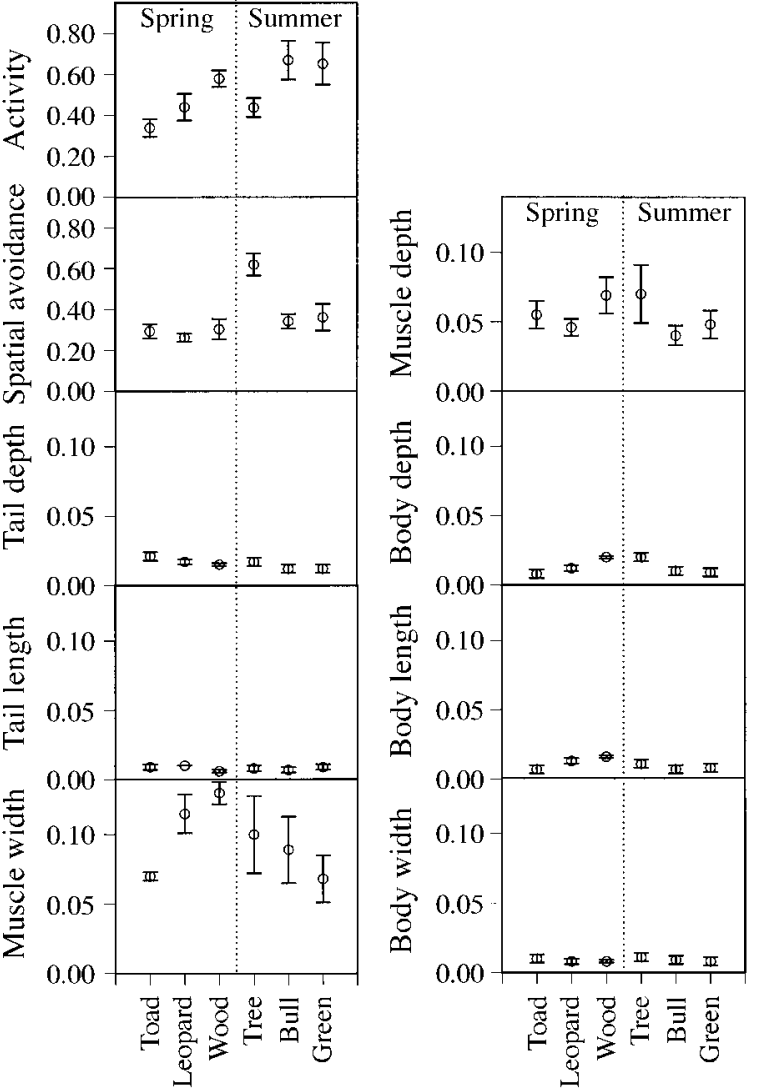

FIG. 6. Plasticity of anuran behavior and morphology as measured by the coefficient of variation across five predator environments for each anuran (see Methods: Comparisons of plasticity for a more detailed explanation of plasticity calculation). Note that the behavioral plasticities (activity and spatial avoidance) are graphed on a higher scale than the morphological plasticities.

morphological responses to invertebrate predators (Hebert 1978, Barry and Bayly 1985, Dodson 1988, Spitze 1992). For larval anurans, I have found that different populations of wood frogs exhibit different morphological responses to the presence of Anax (Relyea 1998).

Behaviorally, the six species also did not respond the same way to a particular predator. For example, in the presence of Umbra, only bullfrogs, leopard frogs, and treefrogs exhibited significant spatial avoidance. Such prey-specific behavior has been observed in many other taxa as well (Sih 1987). Prey-specific activity responses to the same predator have been frequently observed in many studies of anurans (Lawler 1989, Werner 1991, Azevedo-Ramos et al. 1992) as well as aquatic and terrestrial insects (Feener 1981, Williams 1986, Kohler and McPeek 1989, Peckarsky 1996). There appears to be less research on prey-specific, spatial avoidance of predators, but the available data suggest that it may also be common. For example, Kohler and McPeek (1989) found that Glossosoma mayflies were invulnerable to predation and did not respond to the presence of predatory sculpins (Cottus bairdi), whereas the vulnerable Baetis mayflies made more frequent use of refuge habitat in the presence of sculpin. Further prey-specific spatial avoidance examples include freshwater fish and other species of tadpoles (Lawler 1989, Eklov and Persson 1996). These studies suggest that the prey-specific responses to predators are probably widespread, which supports the more general observation that species and populations often differ in their plastic response to different environments (Schlichting 1986).

\section{Predator-specific responses}

Each prey species also exhibited predator-specific responses. For example, leopard frogs increased their tail fin depth only in the presence of Umbra and not in the presence of Anax, Notophthalmus, or Dytiscus. In contrast, wood frogs developed a deeper tail fin in the presence of Umbra and Anax, a moderately deep tail fin in the presence of Notophthalmus, and exhibited no change in tail fin depth in the presence of Dytiscus (relative to the no-predator treatment). This pattern is repeated in other morphological responses as well as the behavioral responses. Thus, it appears that different species of predators induce different morphological and behavioral responses. In other words, it appears that larval anurans can discriminate between species of predators.

The ability to discriminate among predators should be useful in permitting prey to respond appropriately to the presence of predators. Individuals must balance the conflicting costs and benefits of antipredator responses to maximize fitness; responding too strongly incurs unnecessarily high costs (typically reduced growth, see below), whereas not responding strongly enough incurs an unnecessarily high risk of predation. Discriminating among predator species has been frequently observed in behavioral responses, and the response is often related to the risk posed by each of the predators (see review by Sih 1987). However, most of these studies have been limited to two species of predators, and this limits reliability of any general relationship about the combinations of antipredator traits that are expressed. In a companion paper, I demonstrate that there is not a general relationship between risk and response for the larval anurans in this study (Relyea 2001). In contrast to behavioral responses, our previous understanding of predator-specific morphological responses has been restricted to studies of aquatic invertebrates. Researchers have found that protozoans (Kuhlmann and Heckmann 1994, Kusch 1995), rotifers (Stemberger and Gilbert 1987), and cladocerans (Dodson 1988, Black 1993) produce different morphological phenotypes in the presence of different predators. Predator-specific changes in morphology have been previously undescribed in larval amphibians; the current study suggests that they may be common. In sum, it 


\section{Leopard frogs}

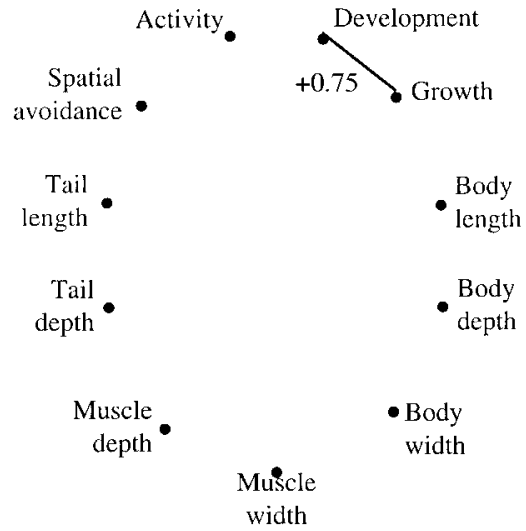

Toads
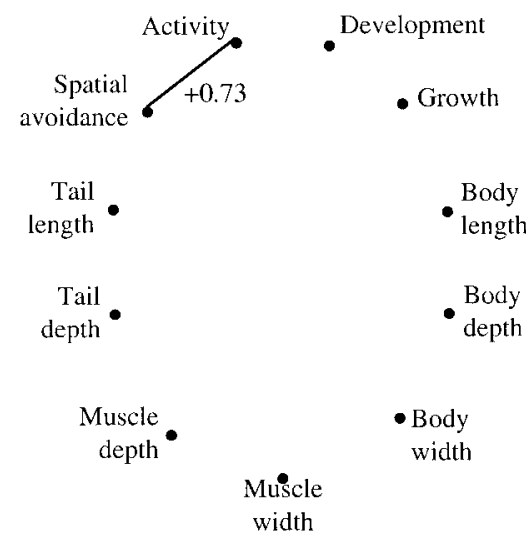

\section{Wood frogs}

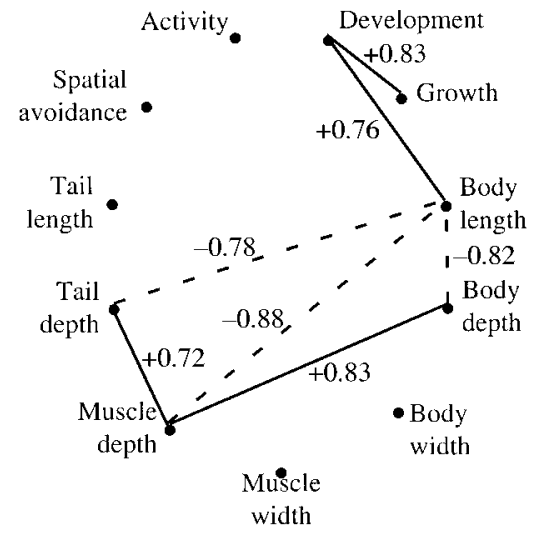

\section{Bullfrogs}

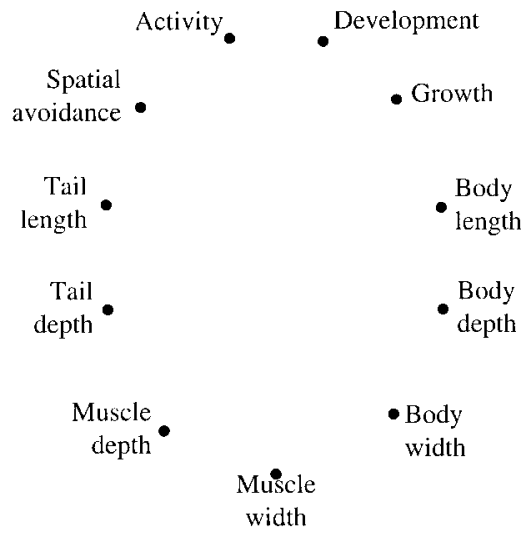

Green frogs
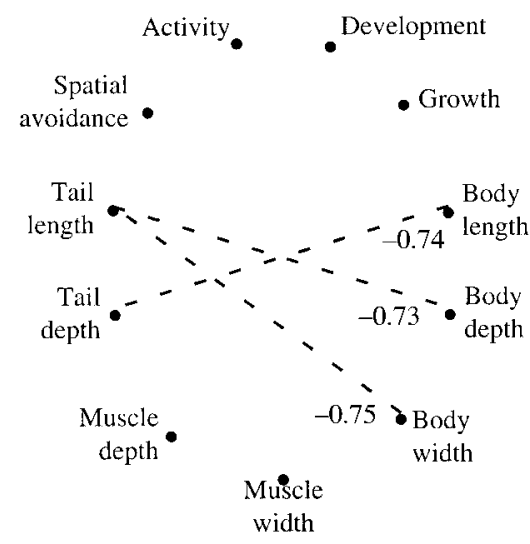

\section{Treefrogs}

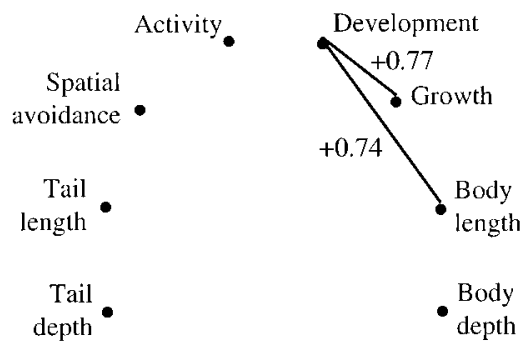

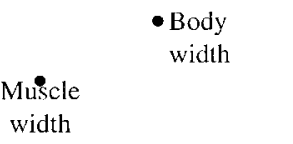

FIG. 7. Trait integration of six species of larval anurans in the presence of five different predator treatments (see Methods for the specific predation treatments). Solid lines indicate positive trait correlations, whereas dashed lines indicate negative trait correlations. 
No predator
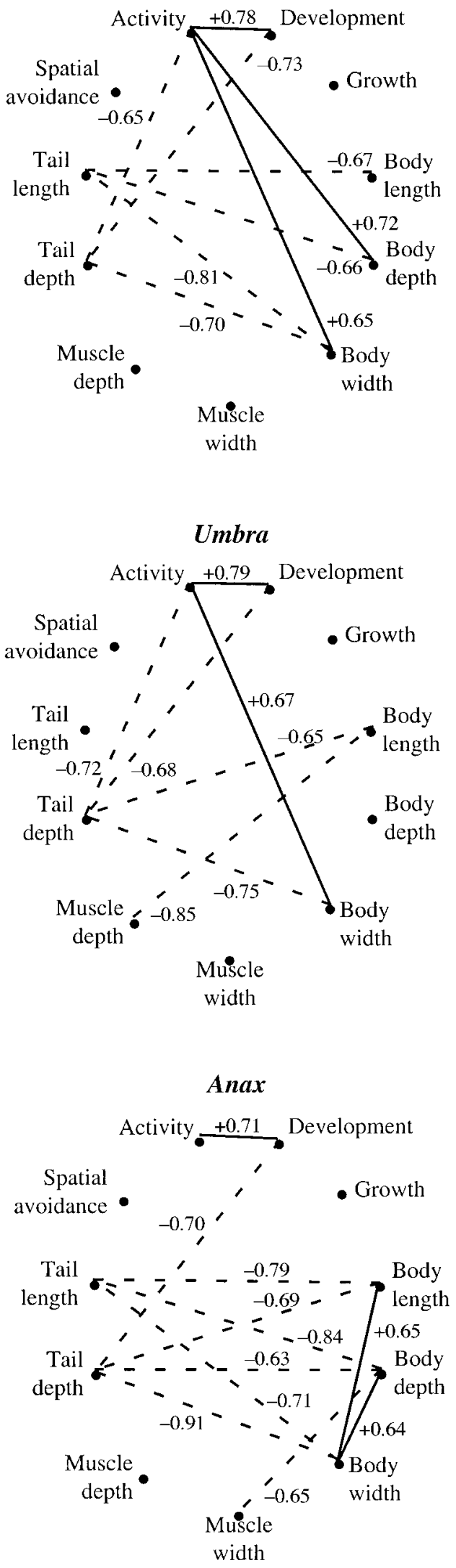

appears that a wide variety of animals, as well as plants (see review by Karban and Baldwin 1997), possess the ability to mount predator-specific defenses.

The ability of tadpoles to discriminate among species of predators may be either a response to unique predator cues or to different concentrations of the same cue. If the latter were true, then the relative magnitude of response to different predators (but not necessarily the direction) should be consistent across different prey. This trend was not observed in my data. For example, toad activity was moderately reduced with Umbra and strongly reduced with Anax while wood frog activity was strongly reduced with Umbra and moderately reduced with Anax; this argues against the hypothesis that Anax emits more cue. This conclusion can be countered by the hypothesis that each predator emits different amounts of a single chemical cue, but the prey are interpreting the cue concentrations differently. In other words, if Anax emitted more cue than Umbra, a toad that detects a large cue will respond by reducing activity more than a toad that detects a small cue whereas a wood frog that detects a large cue will respond by reducing activity less than a wood frog that detects a small cue. Investigators that have increased the number of Anax have found that the wood frogs maintain their low activity (B. R. Anholt and E. E. Werner, unpublished data) and toads reduce it further (Anholt et al. 1996). Overall, results of this study suggest that the larval anuran prey discriminate among predators by detecting different cues rather than different concentrations of the same cue. This conclusion is consistent with work on zooplankton (Havel 1987) and may also be true in plants (Karban and Baldwin 1997).

\section{Adaptiveness of the responses}

Many of the behavioral and morphological responses documented in this study are likely adaptive responses that provide antipredator benefits but may incur costs in predator-free environments (Via and Lande 1985, 1987, West-Eberhard 1989). Spatial avoidance decreases the frequency of predator-prey interactions and should result in decreased prey mortality at the cost of lower growth as prey concentrate in refuge areas and cause increased competition for resources (Werner et al. 1983, Werner and Hall 1988, Leibold 1990, Neill 1990, Bollins and Frost 1991, Ringelberg 1991). Similarly, reduced activity is predicted to reduce predation risk at a cost of lower resource acquisition and growth (Gerritsen and Strickler 1977, Houston et al. 1993, Werner and Anholt 1993, McNamara and Houston 1994) and this has been repeatedly observed in em-

FIG. 8. Trait integration within a predator environment among six species of larval anurans. Solid lines indicate positive trait correlations, whereas dashed lines indicate negative trait correlations. 
pirical tests (Woodward 1983, Werner 1991, Juliano and Reminger 1992, Short and Holomuzki 1992, Semlitsch 1993, Grill and Juliano 1996, Relyea and Werner 1999). In larval amphibians, lower growth is associated with increased susceptibility to pond drying, lower survivorship following metamorphosis, and smaller size at age of first reproduction (Berven and Gill 1983, Smith 1983, Newman 1988, Semlitsch et al. 1988).

We know far less about the adaptiveness of predatorinduced morphological responses of prey. Most work has been conducted on aquatic invertebrates, especially rotifers and cladocerans, and researchers have found that prey reared in the presence of predators often produce protective spines that lower their risk of predation (reviewed by Havel 1987, Harvell 1990). However, in the absence of predators, the spined morph often grows, develops, or reproduces more slowly than the unspined morph. This is the type of phenotypic trade-off expected for plasticity to evolve (Via and Lande 1985, 1987, Via 1987, Gomulkiewicz and Kirkpatrick 1992).

We are only beginning to understand the potential trade-offs involved in altering morphological traits. Previous studies suggest a phenotypic trade-off between tail size and body size in larval anurans. Chorus frogs and Cope's gray treefrogs reared in the presence of the predators (aeshnid dragonflies) develop a deeper tail fin and smaller body and these morphs survived predation better than individuals reared in the absence of predators (Smith and Van Buskirk 1995, McCollum and Van Buskirk 1996, McCollum and Leimberger 1997). Subsequent studies have demonstrated that even within each morph, dragonflies preferentially kill individuals with shallower tail fins and larger bodies but individuals with this morphology grow faster in the absence of predators (Van Buskirk et al. 1997, Van Buskirk and Relyea 1998). This antagonism of costs and benefits of the two phenotypes in the two environments is the mechanism that selects for plastic responses to predators in larval anurans.

The trait correlations of wood frogs, which exhibit a high degree of trait integration, offer an additional opportunity to investigate potential morphological trade-offs in larval anurans. Dytiscus, Notophthalmus, Anax, and Umbra induced progressively deeper tails, deeper muscles, and smaller bodies. Of course, given that these studies (and see Results) have all controlled for overall size before analyzing morphology, any increase in tail fin depth has to be associated with a decrease in some other dimension. This other dimension could have occurred anywhere in the tadpole, but the fact that it consistently occurs in the body suggests that the association of a deeper tail and a smaller body may represent an unavoidable energetic trade-off between the building a deeper tail fin to avoid predators and building a larger body, which may be able to harvest and digest food faster or more efficiently.

The potential phenotypic trade-off observed within the wood frog treatments also was observed among species using all six species in each of the three common predator treatments within individual predator treatments (Fig. 8); when species possessed large tail fins, they also possessed small bodies. These data suggest that there may be evolutionary trade-offs; species that evolve large tail fins also evolve small bodies. Thus, the phenotypic patterns among species may inform us of potential trade-offs of different morphs within a species.

As reviewed above, the costs of expressing antipredator responses should reduce tadpole growth and development but this did not occur in my study. This result is not surprising given that individuals were fed a fixed, per-capita food ration, in isolation from a more natural ecological context. Spatial avoidance, reduced activity, and smaller bodies only pose a cost if a competing organism can consume the surplus food. Because growth is a function of resource levels (Werner and Anholt 1996, Van Buskirk and Yurewicz 1998) and developmental rate is highly correlated to growth rate (Travis et al. 1987, Blouin 1992), the fixed amount of food among predator treatments (within a prey species) resulted in similar growth and development across treatments. In contrast, food rations differed across prey species and species exhibited large differences in growth and development. Species that grew faster on the initial food ration (implying interspecific differences in completeness of food removal or efficiency of growth) received a greater amount of food (although still $6 \%$ of individual body mass).

In more natural experimental systems, the plastic responses of anurans to predators do incur costs to prey growth and development. For example, Werner and Anholt (1996) reared vulnerable first-year bullfrogs and green frogs and invulnerable second-year bullfrogs under different levels of competition and in the presence and absence of caged Anax. The reduced activity of the vulnerable tadpole classes resulted in reduced growth of both classes, whereas the invulnerable tadpole class experienced increased growth. This pattern has been repeated in several other experiments in which the predator-induced change in behavior or morphology of prey has resulted in altered growth and development (Sih 1987, Lima and Dill 1990, Skelly 1992, Werner and Anholt 1996, Relyea and Werner 1999, Relyea 2000)

\section{Comparative plasticity}

The analysis of comparative plasticity demonstrated that behavior was more plastic than morphology. This result supports conventional wisdom (West-Eberhard 1989) but appears to be the first quantitative test of the hypothesis. Behavior is thought to be more plastic because it is highly reversible; incorrect behavioral decisions can be quickly corrected. Further, changes in behavior often involve simply doing more or fewer repetitions of the same behavior (e.g., spending a higher percentage of the day being active). Thus, behavioral 
responses can be relatively short-term responses to predators. In contrast, changes in morphology are typically irreversible or more slowly reversible because they involve structures that cannot be rapidly broken down. Thus, morphological responses must be relatively long-term responses to a constant predator presence.

A second dominant pattern was that species exhibited few differences in the plasticity of their traits. Of the nine behavioral and morphological traits observed, only four traits (activity, spatial avoidance, muscle width, and body length) differed among species. Such differences may be related to historical differences in the heterogeneity of the predator environments that each species has experienced (West-Eberhard 1989). Our understanding of predator heterogeneity in natural ponds is still in its early stages (E. E. Werner et al., unpublished data); thus, we cannot yet evaluate this hypothesis. In the combined analysis, only spatial avoidance differed among prey species; however, the combined analysis estimated plasticity from only three environments, potentially restricting the range of plasticity that could be observed. The comparative plasticity results improve our understanding of comparative plasticity in larval anurans from an earlier study (Relyea and Werner 1999) in which the morphological plasticity of the four species in the genus Rana were only reared in the presence of one predator species (Anax). In that study, wood frogs and leopard frogs developed deeper tail fins and shorter bodies in the presence of Anax, whereas green frogs and bullfrogs did not. Thus, it appeared that the ranid species differed in their plasticity of tail depth and body length. Based on the results of the present study, a more reasonable interpretation is that the species have similar plastic abilities for most traits (including tail depth and body length) and that examining responses to a single predator species can present a misleading picture of an organism's plastic ability because some plastic responses are not expressed in single predator experiments.

\section{Trait correlations}

There were relatively few significant trait correlations for each species exposed to different predator environments, demonstrating that larval anurans are using unique suites of traits against each species of predator. If prey had been using a scaled set of a single suite of responses against predators (e.g., small reductions in activity and body length with one predator and large reductions in activity and body length with a second predator), we would observe a high number of trait correlations for each prey. Because there is evidence that many of these responses are adaptive, each prey may be producing predator-specific responses that are best adapted to each predator. If this is the case, then it further suggests that the suite of phenotypes produced in the presence of one predator should not serve as a general defense against other predators. Tests of this hypothesis appear to be an open area of research in larval amphibians, but Havel's (1985) work suggests that the hypothesis is supported in cladocerans.

The trait correlation results also have implications for the evolution of phenotypic plasticity. If the phenotypic correlations are related to genetic correlations between traits, then selection within an environment on one trait will cause correlated selection on other traits within that environment (Lande and Arnold 1983) as well as indirect selection on traits in each of the other environments (Via and Lande 1985, 1987, Via 1987). A high number of trait correlations across environments would favor the selection of other adaptive antipredator traits whereas a low number of trait correlations would oppose the selection of other adaptive antipredator traits.

The analysis of trait correlations among the six species reared in the same predator environment suggest an important role of the abiotic environment in shaping larval anuran phenotypes. One consistent pattern was that faster developing anurans possessed higher activity levels. Only fast developing anurans (e.g., toads and treefrogs) can inhabit the most ephemeral habitats, and high activity, which permits a greater acquisition of resources (Sih 1987, Lima and Dill 1990, Werner 1991, Relyea and Werner 1999), should result in rapid growth and development to permit metamorphosis before the pond dries. Thus, pond permanence appears to have an important effect on general activity level. A second pattern to arise was that these species of more temporary ponds also possessed smaller tails and larger bodies, a pattern that has also been observed in chorus frogs (Smith and Van Buskirk 1995). Van Buskirk and Relyea (1998) and Van Buskirk et al. (1997) have shown that, within species, wood frog and chorus frog individuals that possess shallower tails and larger bodies grow faster than individuals with deeper tails and smaller bodies. A possible functional explanation is that the larger body provides increased surface area for food harvesting and digestion. If this within-species pattern can be applied between species, then it suggests that species of more ephemeral habitats are more active and possess relatively smaller tail fins and larger bodies as adaptations for more rapid growth and development. Clearly, these are hypotheses in need of additional empirical tests.

\section{CONCLUSiOnS}

I have demonstrated that an organism's response to different predator environments can be highly prey and predator specific. This means that to properly address questions concerning the magnitude of plasticity among species and among different types of species traits, responses to several different environments must be observed. Future investigators should determine the cues that prey use to identify particular predators and the phenotypic decisions prey make when different predator species are present simultaneously. It is cru- 
cial that we also investigate the costs and benefits, if any, of many prey responses that are currently unknown (e.g., decreases in tail fin depth). Finally, it is essential that we better understand how correlations among traits, both phenotypic and genetic, differ across environments and how these correlations affect the evolution of phenotypic plasticity.

\section{ACKNOWLEDGMENTS}

I thank Scott Peacor for assistance with the field work, Sharmista JES'Son-Relyea for assistance in digitizing the tadpoles, and Ronald Nussbaum and Richard Alexander for providing access to the E. S. George Reserve. This manuscript was greatly improved by David Allan, Deborah Goldberg, Ron Nussbaum, Earl Werner, and Kerry Yurewicz. This work was supported by University of Michigan research grants and NSF grants DEB-9119948 and DEB-9408397.

\section{Literature Cited}

Anholt, B. R., D. K. Skelly, and E. E. Werner. 1996. Factors modifying antipredator behavior in larval toads. Herpetologica 52:301-313.

Anholt, B. R., and E. E. Werner. 1995. Interaction between food availability and predation mortality mediated by adaptive behavior. Ecology 76:2230-2234.

Azevedo-Ramos, C., M. Van Sluys, J. Hero, and W. E. Magnusson. 1992. Influence of tadpole movement on predation by odonate naiads. Journal of Herpetology 26:335-338.

Barry, M. J., and I. A. E. Bayly. 1985. Further studies on predator induction of crests in Australian Daphnia and the effects of crests on predation. Australian Journal of Marine and Freshwater Research 36:519-535.

Belsky, A. J. 1986. Does herbivory benefit plants? A review of the evidence. American Naturalist 127:870-892.

Berven, K. A., and D. E. Gill. 1983. Interpreting geographic variation in life-history traits. American Zoologist 23:8597.

Black, A. R. 1993. Predator-induced phenotypic plasticity in Daphnia pulex: life history and morphological responses to Notonecta and Chaoborus. Limnology and Oceanography 38:986-996.

Blouin, M. S. 1992. Genetic correlations among morphometric traits and rates of growth and differentiation in the green treefrog, Hyla cinerea. Evolution 46:735-744.

Bollins, S. M., and B. W. Frost. 1991. Diel vertical migration in zooplankton: rapid individual response to predators. Journal of Plankton Research 13:1359-1365.

Bookstein, F. L. 1991. Morphometric tools for landmark data. Cambridge University Press, Cambridge, UK.

Bradshaw, A. D. 1965. Evolutionary significance of phenotypic plasticity in plants. Advances in Genetics 13:115155.

Brönmark, C., and J. G. Miner. 1992. Predator-induced phenotypical change in body morphology in Crucian carp. Science 258:1348-1350.

Chovanec, A. 1992. The influence of tadpole swimming behaviour on predation by dragonfly nymphs. Amphibia-Reptilia 13:341-349.

Clausen, J., D. D. Heck, and W. Hiesey. 1941. Experimental studies on the nature of plant species. I. The effect of varied environments on western North American plants. Carnegie Institute of Washington Publication, Number 520, Washington, D.C., USA.

Cook, S. A., and M. P. Johnson. 1968. Adaptation to heterogeneous environments. I. Variation in heterophylly in Ranunculus flammula L. Evolution 22:496-516.

Crick, J. C., and J. P. Grime. 1987. Morphological plasticity and mineral nutrient capture in two herbaceous species of contrasted ecology. New Phytology 107:403-414.
Crowl, T. A., and A. P. Covich. 1990. Predator-induced lifehistory shifts in a freshwater snail. Science 247:949-951.

Dodson, S. 1988. The ecological role of chemical stimuli for the zooplankton: predator-avoidance behavior in Daphnia. Limnology and Oceanography 33:1431-1439.

Dudley, S. A., and J. Schmitt. 1996. Testing the adaptive plasticity hypothesis: density-dependent selection on manipulated stem length in Impatiens capensis. American Naturalist 147:445-465.

Eklöv, P., and L. Persson. 1996. The response of prey to the risk of predation: proximate cues for refuging juvenile fish. Animal Behaviour 51:105-115.

Feener, D. H. J. 1981. Competition between ant species: outcome controlled by parasitic flies. Science 214:815-817.

Feminella, J. W., and C. P. Hawkins. 1994. Tailed frog tadpoles differentially alter their feeding behavior in response to non-visual cues from four predators. Journal of the North American Benthological Society 13:310-320.

Gerritsen, J., and J. R. Strickler. 1977. Encounter probabilities, and the community structure in zooplankton: a mathematical model. Journal of the Fisheries Board of Canada 34:73-82.

Gomulkiewicz, R., and M. Kirkpatrick. 1992. Quantitative genetics and the evolution of reaction norms. Evolution 46: 390-411.

Gosner, K. L. 1960. A simplified table for staging anuran embryos and larvae with notes on identification. Herpetologica 16:183-190.

Grill, C. P., and S. A. Juliano. 1996. Predicting species interactions based on behaviour: predation and competition in container-dwelling mosquitoes. Journal of Animal Ecology 65:63-76.

Harvell, C. D. 1990. The ecology and evolution of inducible defenses. Quarterly Review of Biology 65:323-340.

Havel, J. E. 1985. Predation of common invertebrate predators on long- and short-featured Daphnia retrocurva. Hydrobiologia 124:141-149.

Havel, J. E. 1987. Predator-induced defenses: a review. Pages 263-278 in W. C. Kerfoot and A. Sih, editors. Predation: direct and indirect impacts on aquatic communities. University Press of New England, Hanover, New Hampshire, USA.

Hebert, P. D. N. 1978. The adaptive significance of cyclomorphosis in Daphnia: more possibilities. Freshwater Biology 8:313-320.

Hiesey, W. M. 1953. Comparative growth between and within climatic races of Achillea under controlled conditions. Evolution 7:297-316.

Horat, P., and R. D. Semlitsch. 1994. Effects of predation risk and hunger on the behaviour of two species of tadpoles. Behavioral Ecology and Sociobiology 34:393-401.

Houston, A. I., J. M. McNamara, and J. M. C. Hutchinson. 1993. General results concerning the trade-off between gaining energy and avoiding predation. Philosophical Transactions of the Royal Society of London B 341:375397.

Jackson, M. E., and R. D. Semlitsch. 1993. Paedomorphosis in the salamander Ambystoma talpoideum: effects of a fish predator. Ecology 74:342-350.

Juliano, S. A., and L. Reminger. 1992. The relationship between vulnerability to predation and behavior of larval treehole mosquitoes: geographic and ontogenetic differences. Oikos 63:465-476.

Karban, R., and I. T. Baldwin. 1997. Induced responses to herbivory. University of Chicago Press, Chicago, Illinois, USA.

Kats, L. B., J. W. Petranka, and A. Sih. 1988. Antipredator defenses and the persistence of amphibian larvae with fishes. Ecology 69:1865-1870.

Kingsolver, J. G. 1995a. Fitness consequences of seasonal 
polyphenism in western white butterflies. Evolution 49 942-954.

Kingsolver, J. G. 1995b. Viability selection on seasonally polyphenic traits: wing melanin pattern in western white butterflies. Evolution 49:932-941.

Kohler, S. L., and M. A. McPeek. 1989. Predation risk and the foraging behavior of competing stream insects. Ecology 70:1811-1825.

Kuhlmann, H.-W., and K. Heckmann. 1994. Predation risk of typical ovoid and winged morphs of Euplotes (Protozoa, Ciliophora). Hydrobiologia 284:219-227.

Kusch, J. 1995. Adaptation of inducible defense in Euplotes daidaleos (Ciliophora) to predation risks by various predators. Microbial Ecology 30:79-88.

Lande, R., and S. J. Arnold. 1983. The measurement of selection on correlated characters. Evolution 37:1210-1226.

Lawler, S. P. 1989. Behavioural responses to predators and predation risk in four species of larval anurans. Animal Behaviour 38:1039-1047.

Leibold, M. 1990. Resources and predators can affect the vertical distributions of zooplankton. Limnology and Oceanography 35:938-944.

Lima, S. L., and L. M. Dill. 1990. Behavioral decisions made under the risk of predation: a review and prospectus. $\mathrm{Ca}$ nadian Journal of Zoology 68:619-640.

Marshall, D. R., and S. K. Jain. 1969. Interference in pure and mixed populations of Avena fatua and A. Barbata. Journal of Ecology 57:251-270.

McCollum, S. A., and J. D. Leimberger. 1997. Predator-induced morphological changes in an amphibian: predation by dragonflies affects tadpole shape and color. Oecologia 109:615-621.

McCollum, S. A., and J. Van Buskirk. 1996. Costs and benefits of a predator-induced polyphenism in the gray treefrog Hyla chrysoscelis. Evolution 50:583-593.

McGraw, J. B., and J. Antonovics. 1983. Experimental ecology of Dryas octopetala ecotypes. Journal of Ecology 71: 879-897.

McNamara, J. M., and A. I. Houston. 1994. The effect of a change in foraging options on intake rate and predation rate. American Naturalist 144:978-1000.

McNaughton, S. J., and F. S. Chapin, III. 1985. Effects of phosphorous nutrition and defoliation on $\mathrm{C}_{4}$ graminoids from the Serengeti plains. Ecology 66:1617-1629.

Moran, N. A. 1991. Phenotypic fixation and genotypic diversity in the complex life cycle of the aphid Pemphigus betae. Evolution 45:957-970.

Neill, W. E. 1990. Induced vertical migration in copepods as a defence against invertebrate predation. Nature 345:524526.

Newman, R. A. 1988. Adaptive plasticity in development of Scaphiopus couchii tadpoles in desert ponds. Evolution 42 : $774-783$

Paige, K. N., and T. G. Whitham. 1987. Overcompensation in response to mammalian herbivory: the advantage of being eaten. American Naturalist 129:407-416.

Peckarsky, B. L. 1996. Alternative predator avoidance syndromes of stream-dwelling mayfly larvae. Ecology 77: 1888-1905.

Petranka, J. W., L. B. Kats, and A. Sih. 1987. Predator-prey interactions among fish and larval amphibians: use of chemical cues to detect predatory fish. Animal Behavior 35:420-425.

Pfennig, D. W. 1992. Polyphenism in spadefoot toad tadpoles as a locally adjusted evolutionary stable strategy. Evolution 46: $1408-1420$.

Rahn, H. 1967. Gas transport from the external environment to the cell. Pages 3-29 in A. V. S. de Reuck and R. Porter, editors. Development of the lung. Churchill, London, UK.

Relyea, R. A. 1998. Phenotypic plasticity in larval anurans.
Dissertation. University of Michigan, Ann Arbor, Michigan, USA.

Relyea, R. A. 2000. Trait-mediated indirect effects in larval anurans: reversing competition with the threat of predation. Ecology 81:2278-2289.

Relyea, R. A. 2001. The relationship between predation risk and antipredator responses in larval anurans. Ecology 82: 541-554.

Relyea, R. A., and E. E. Werner. 1999. Quantifying the relation between predator-induced behavior and growth performance in larval anurans. Ecology 80:2117-2124.

Relyea, R. A., and E. E. Werner. 2000. Morphological plasticity of four larval anurans distributed along an environmental gradient. Copeia 2000:178-190.

Rieck, A. F., J. A. Belli, and M. E. Blaskovics. 1960. Oxygen consumption of whole animals and tissues in temperature acclimated amphibians. Proceedings of the Society of Experimental Biology and Medicine 103:436-439.

Ringelberg, J. 1991. Enhancement of the phototactic reaction in Daphnia hyalina by a chemical mediated by juvenile perch (Perca fluviatilis). Journal of Plankton Research 13: 17-25.

Scheiner, S. M., and C. J. Goodnight. 1984. The comparison of phenotypic plasticity and genetic variation in populations of the grass Danthonia spicata. Evolution 38:845855 .

Schlichting, C. D. 1986. The evolution of phenotypic plasticity in plants. Annual Review of Ecology and Systematics 17:667-693.

Schlichting, C. D., and D. A. Levin. 1984. Phenotypic plasticity of annual Phlox: tests of some hypotheses. American Journal of Botany 71:252-260.

Schmitz, O. J., A. P. Beckerman, and K. M. O'Brien. 1997. Behaviorally mediated trophic cascades: effects of predation risk on food web interactions. Ecology 78:1388-1399.

Semlitsch, R. D. 1993. Effects of different predators on the survival and development of tadpoles from the hybridogenetic Rana esculenta complex. Oikos 67:40-46.

Semlitsch, R. D., D. E. Scott, and J. H. K. Pechmann. 1988 Time and size at metamorphosis related to adult fitness in Ambystoma talpoideum. Ecology 69:184-192.

Short, T. M., and J. R. Holomuzki. 1992. Indirect effects of fish on foraging behaviour and leaf processing by the isopod Lirceus fontinalis. Freshwater Biology 27:91-97.

Sih, A. 1987. Predators and prey lifestyles: an evolutionary and ecological overview. Pages 203-224 in W. C. Kerfoot and A. Sih, editors. Predation: direct and indirect impacts on aquatic communities. University Press of New England, Hanover, New Hampshire, USA.

Skelly, D. K. 1992. Field evidence for a cost of behavioral antipredator response in a larval amphibian. Ecology 73: 704-708.

Skelly, D. K. 1994. Activity level and the susceptibility of anuran larvae to predation. Animal Behaviour 47:465-468.

Skelly, D. K., and E. E. Werner. 1990. Behavioral and lifehistorical responses of larval American toads to an odonate predator. Ecology 71:2313-2322.

Smith, D. C. 1983. Factors controlling tadpole populations of the chorus frog (Pseudacris triseriata) on Isle Royale, Michigan. Ecology 64:501-510.

Smith, D. C., and J. Van Buskirk. 1995. Phenotypic design, plasticity, and ecological performance in two tadpole species. American Naturalist 145:211-233.

Spitze, K. 1992. Predator-mediated plasticity of prey lifehistory and morphology: Chaoborus americanus predation on Daphnia pulex. American Naturalist 139:229-247.

Stemberger, R. S., and J. J. Gilbert. 1987. Multiple species induction of morphological defense in the rotifer, Keratella testudo. Ecology 68:370-378. 
Sultan, S. E. 1987. Evolutionary implications of phenotypic plasticity in plants. Evolutionary Biology 21:127-177.

Tejedo, M. 1993. Size-dependent vulnerability and behavioral responses of tadpoles of two anuran species to beetle larvae predators. Herpetologica 49:287-294.

Travis, J., S. Emerson, and M. Blouin. 1987. A quantitativegenetic analysis of larval life history traits in Hyla crucifer. Evolution 41:145-156.

Turner, A. M., and G. G. Mittelbach. 1990. Predator avoidance and community structure: interactions among piscivores, planktivores, and plankton. Ecology 71:2241-2254.

Van Buskirk, J., S. A. McCollum, and E. E. Werner. 1997. Natural selection for environmentally-induced phenotypes in tadpoles. Evolution 52:1983-1992.

Van Buskirk, J., and R. A. Relyea. 1998. Natural selection for phenotypic plasticity: predator-induced morphological responses in tadpoles. Biological Journal of the Linnean Society 65:301-328.

Van Buskirk, J., and K. L. Yurewicz. 1998. Effects of predators on prey growth rate: relative contributions of thinning and reduced activity. Oikos 82:20-28.

Via, S. 1987. Genetic constraints on the evolution of phenotypic plasticity. Pages 47-71 in V. Loeschke, editor. Genetic constraints on adaptive evolution. Springer-Verlag, Berlin, Germany.

Via, S., R. Gomulkiewicz, G. De Jong, S. M. Scheiner, C. D. Schlichting, and P. H. Van Tienderen. 1995. Adaptive phenotypic plasticity: consensus and controversy. Trends in Ecology and Evolution 10:212-217.

Via, S., and R. Lande. 1985. Genotype-environment interaction and the evolution of phenotypic plasticity. Evolution 39:502-522.
Via, S., and R. Lande. 1987. Evolution of genetic variability in a spatially heterogeneous environment: effects of genotype-environment interaction. Genetic Research 49: $147-156$.

Werner, E. E. 1991. Nonlethal effects of a predator on competitive interactions between two anuran larvae. Ecology 72:1709-1720.

Werner, E. E., and B. R. Anholt. 1993. Ecological consequences of the trade-off between growth and mortality rates mediated by foraging activity. American Naturalist 142: 242-272.

Werner, E. E., and B. R. Anholt. 1996. Predator-induced behavioral indirect effects: consequences to competitive interactions in anuran larvae. Ecology 77:157-169.

Werner, E. E., J. F. Gilliam, D. J. Hall, and G. G. Mittelbach 1983. An experimental test of the effects of predation risk on habitat use in fish. Ecology 64:1540-1548.

Werner, E. E., and D. J. Hall. 1976. Niche shifts in sunfishes: experimental evidence and significance. Science 191:404406.

Werner, E. E., and D. J. Hall. 1988. Ontogenetic habitat shifts in bluegill: the foraging rate-predation risk trade-off. Ecology 69:1352-1366.

West-Eberhard, M. J. 1989. Phenotypic plasticity and the origins of diversity. Annual Review of Ecology and Systematics 20:249-278.

Williams, D. D. 1986. Factors influencing the microdistribution of two sympatric species of Plecoptera: an experimental study. Canadian Journal of Fisheries Science 43: $1005-1009$

Woodward, B. D. 1983. Predator-prey interactions and breeding-pond use of temporary-pond species in a desert anuran community. Ecology 64:1549-1555. 